\title{
Que urbano é esse? O habitat num espaço de transição do norte de Pernambuco
}

\author{
JOSÉ GRABOIS
}

$\mathrm{E}$

STE ARTIGO É PARTE de um trabalho maior, cuja proposta é evidenciar como o surgimento e a evolução das formas do habitat existentes nas Terras Altas, especialmente naquelas ligadas à pequena produção, encontram-se fortemente vinculadas à histórica relação de subordinação da pequena à grande produção.

Nossa análise orienta-se no sentido de demonstrar que o habitat é o resultado de sucessivas etapas de povoamento que, por sua vez, estão ligadas à evolução da economia e da sociedade em dado espaço.

A área em estudo localiza-se no extremo noroeste da Mata Norte de Pernambuco, já na sua passagem para o Agreste. Assim, fica estabelecida uma transição complexa entre três espaços com características fisiográficas, ecológicas e de ocupação muito próprias: a Mata, domínio da cana-deaçúcar, o Agreste com a pecuária e o Brejo, a serra do Mascarenhas. De um modo geral pode-se subdividir a área em dois grandes espaços: a Área Nuclear, a que também chamamos de Brejo de São Vicente, onde as feições de brejo se apresentam mais acentuadas e que se acha envolvida em todo o seu perímetro por um cinturão de largura variável que denominamos Faixa ou Anel de Transição Complexa. Esta última constitui um espaço bastante diversificado porque aí se projetam, além das características da Área Nuclear, as influências das terras vizinhas do Agreste e da Mata. Isto nos levou a considerar três setores diferenciados, aos quais chamamos de Setor Norte Oriental ou Canavieiro, Setor Meridional e Setor Ocidental.

Quando tratamos da especificidade do ambiente natural e do processo de ocupação das Terras Altas, estamos partindo da consideração de que os fatores históricos são fundamentais para a estruturação do povoamento e do habitat, relacionados, porém, indissociavelmente à natureza. As transformações da economia e da sociedade, que supõem todo um processo de desenvolvimento das forças produtivas e da evolução das relações sociais de produção, promovem reordenações espaciais onde se incluem aquelas relativas ao habitat, alterando formas de dispersão e concentração. 


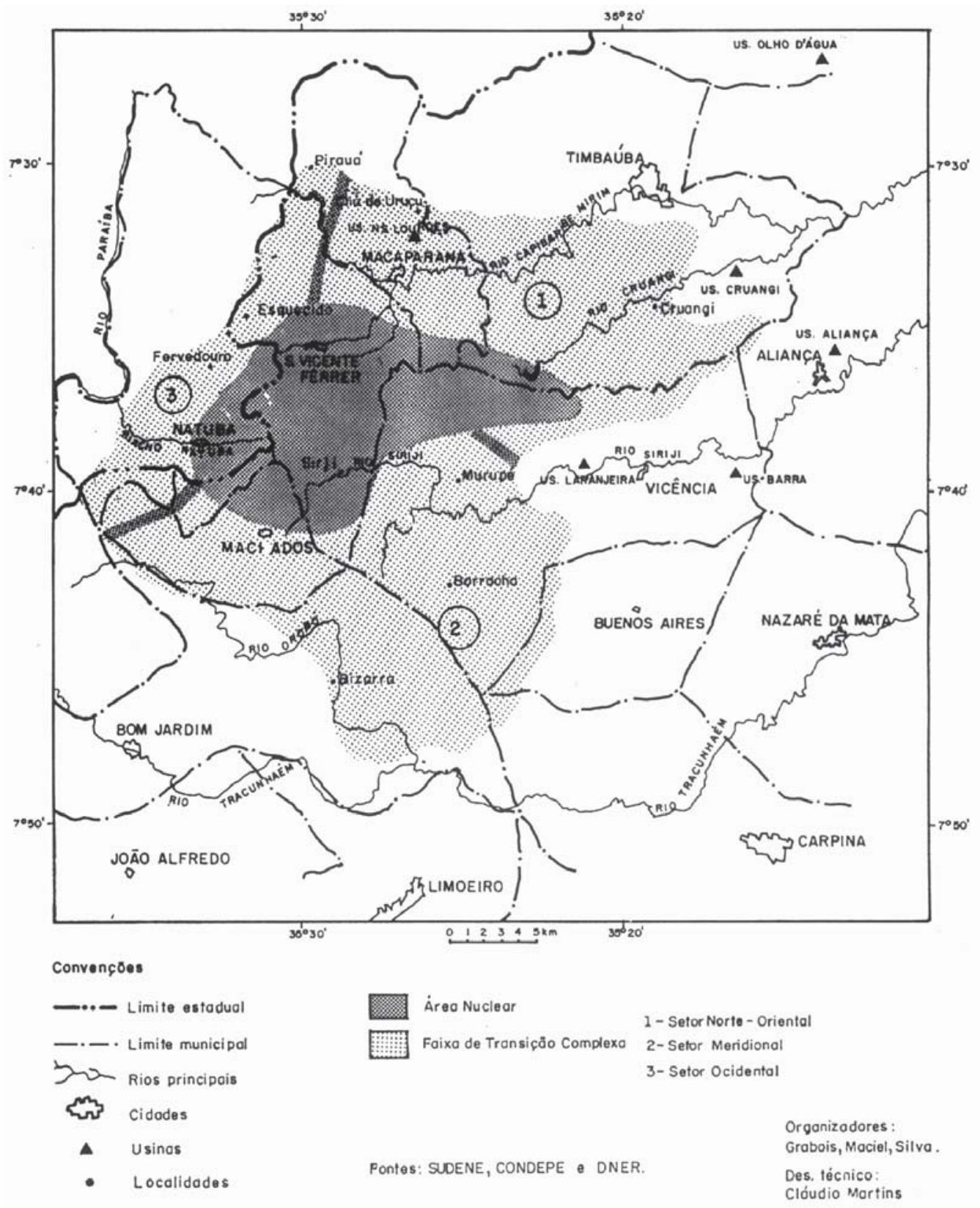

Mapa

Terras altas da transição Agreste-Mata do norte de Pernambuco Delimitação e subdivisão 
Assim, é nosso esforço mostrar como o capitalismo, por meio do engenho, criou em grande parte uma sociedade camponesa de foreiros coexistindo com outros tipos de relação de trabalho como, por exemplo, as que estão contidas no sistema de morada. Essa forma dispersa de povoamento redunda, por necessidades estruturais do sistema, na formação de habitat grupado - povoados, vilas e cidades. Procuramos explicitar, também, como o desenvolvimento capitalista, ao longo dos surtos usineiros, destruiu sua própria criação, alterando profundamente a organização do habitat nas Terras Altas.

Isto nos remete imediatamente a uma visão do habitat como reflexo de uma sociedade de classes, manifesta não só no contraste entre a estrutura das habitações, mas também na sua distribuição espacial. A classe dominante emprega, conforme o momento histórico, diversas estratégias que tanto podem levar à organização de formas dispersas do habitat, quanto a formas grupadas.

Tal é o caso didaticamente representado por São Vicente Férrer e certamente por todas as outras cidades das Terras Altas: como já se disse antes, o engenho criou, além da forma concentrada, concernente à casagrande e demais construções, um habitat disperso representado pelas casas dos camponeses (foreiros) e moradores. O aumento da densidade demográfica decorrente desse fato levou sucessivamente à formação da feira, da freguesia, da vila e da cidade, isto é, a dispersão criou a concentração, com ela coexistindo.

A cidade (ou vila) passa a ser parte do mecanismo de dominação, pois que nela a população rural dispersa, além do sal e do ferro, vai encontrar uma série de serviços, ainda que elementares, que a vão ajudar a se reproduzir. Assim, a sobrevivência da força de trabalho, em parte mediatizada pela cidade, evidentemente é a garantia de viabilização do latifúndio.

Desse modo, criam-se condições para o surgimento de uma classe média urbana de comerciantes, profissionais liberais e funcionários públicos, muitos dos quais vão se tornando médios proprietários rurais, quando não provenientes de famílias de grandes e médios proprietários do local. Não se pode perder a perspectiva de que este universo urbano, por sua vez, gravita em torno dos grandes proprietários, estes efetivamente os donos do poder, os chefes politicos.

A situação atual, que representa uma outra etapa da evolução da economia, traduz-se pelo marcado êxodo rural com a população emigrada ou remanescente assumindo duas formas de distribuição espacial, seja em sua 
expressão dispersa - as paleoformas do habitat - seja, principalmente, em sua manifestação grupada: uma massa de proletários rurais vivendo em ambiente urbano, nas pontas-de-rua (1).

Essa sociedade de classes, na sua dinâmica, mostra exemplarmente nas Terras Altas o que Pierre George (1982:131) chama de "instabilidade do habitat" por conta das transmutações das relações sociais que estão subjacentes à nova distribuição espacial da força de trabalho.

A necessidade crescente de terras por parte da usina, demonstrada a partir dos anos 50 no caso das Terras Altas - principalmente na Faixa de Transição Complexa -, levou à expulsão da grande maioria dos moradores e foreiros, notadamente estes últimos. A usina não queria expulsá-los todos de seus engenhos, preferindo antes que se transformassem em moradores de condição.

Não era só de terras que necessitava para expandir seus canaviais, precisava, isto sim, cada vez mais de braços e a situação do foreiro, cujo contrato permitia lhe trabalhar na maior parte do tempo nas terras de seu sítio, não era tão compatível com as necessidades da usina quanto a do morador de condição, obrigado a dar um número muito maior de dias de trabalho. Esse choque de interesses entre, de um lado, os trabalhadores e, de outro, as usinas e os fornecedores transformou-se em conflito, marcando o aparecimento das Ligas Camponesas. Mas o processo de expulsão também está ligado à Área Nuclear, no caso da expansão dos bananais, e ainda se faz sentir na Faixa de Transição.

O processo de expulsão aumentou gradualmente desde a promulgação do Estatuto da Terra em 1964 e com a implementação dos programas de modernização da agricultura dos anos 70, levando à formação de significativas pontas-de-rua. Todas as cidades e vilas das Terras Altas são marcadas mais ou menos expressivamente por essas periferias, onde se aglomera não só, mas principalmente, uma população de ex-moradores e foreiros e também, em número bem menor, de antigos pequenos proprietários.

O êxodo rural não alcançou nas Terras Altas a intensidade com que se efetivou na Zona da Mata, o que é compatível com a permanência de um número razoável de casas de moradores nos canaviais e bananais, constituindo uma paleoforma do habitat rural.

Deve-se lembrar ainda das comunidades de pequenos proprietários, ex-moradores e foreiros que adquiriram suas terras de proprietários de engenhos, constituindo outra paleoforma do habitat. 


\section{O habitat disperso}

\section{Paleoformas em vias de extinção}

$\mathrm{Na}$ esteira do contínuo esvaziamento do campo, permanecem elementos residuais do habitat que denominamos paleoformas. Um primeiro tipo, que no seu âmago melhor representa o fenômeno da latência, é o que podemos chamar de paleoformas em vias de extinção. Tratam-se de casas de moradores, cada vez mais raras, mais ou menos antigas e de diversos padrões que ainda são vistas nas usinas, engenhos e fazendas de banana das Terras Altas.

Anteriormente, a usina e seus fornecedores tinham interesse em manter trabalhadores em seu território. Sua estratégia apoiava-se na relação de morada: "A concessão do senhor de engenho [casa e roçado] e o reconhecimento a que se obrigava o morador que a recebia, constituíam partes de um único sistema de dominação. A relação assim constituída era o pilar sobre o qual se estruturava a relação de morada" (Herédia, 1988:119).

Os grandes proprietários, necessariamente, conhecendo muito bem seu universo, à medida em que a família do morador aumentava, remanejavam-na, passando-a para uma casa maior; a antiga casa serviria para novos moradores e assim por diante. Esse era o mecanismo fundamental da garantia de reprodução da força de trabalho no interior do engenho ou da usina. A eles se somam o roçado e o endividamento feito no barracão.

Atualmente, o que se assiste é um movimento no sentido contrário, marcado pela saída dos moradores por indenização ou por inércia, permanecendo, neste caso, muitos deles - os mais antigos - em suas casas. Cabe lembrar que um lado da questão, talvez o principal, é que a expulsão de um número muito grande de moradores causaria despesas muito altas com indenizações estabelecidas na justiça do trabalho (2).

Pode-se pensar que boa parte das usinas das Terras Altas, já tendo garantida a sua mão-de-obra nas pontas-de-rua das cidades e dos povoados próximos, adote como política permitir a permanência de antigos moradores até que as famílias vão se desfazendo pela saída dos mais jovens, aos quais não se concede mais moradia, pela morte dos mais velhos, sem qualquer perspectiva de trabalho, e aposentados pelo Funrural.

No comum dos casos, assim que a casa fica vazia é imediatamente derrubada. É o meio mais viável de expulsão de uma massa residual de trabalhadores residentes e ex-trabalhadores. É o último ato que se desenrola lentamente, marcando o fim de uma época. 


\section{Paleoformas funcionais}

A paleoforma funcional é encontrada em algumas propriedades das Terras Altas, particularmente na Usina Cruangi e secundariamente na Usina N. S. de Lourdes; ocorre, além disso, entre numerosos fornecedores proprietários e grandes produtores de banana. Na maior parte dos casos, é mantido um mínimo necessário de moradores: a pesquisa mostrou que habitualmente cerca de $20 \%$ do número de moradores existentes no auge do sistema de morada permanecem, isto é, antes do primeiro surto usineiro que afetou as Terras Altas.

Enquanto a primeira forma citada, representando mais autenticamente o fenômeno da latência, tende a se extinguir, as paleoformas funcionais, pelo menos até 1993, mantiveram uma certa estabilidade. Não acreditamos que elas representem rigorosamente a latência, mas talvez a sua representação atual calcada na recriação da forma antiga.

Essa forma é paradoxal porque marcada pela presença de um habitat disperso - e certamente menos denso do que as formas originais - dado pelas casas dos moradores num anacronismo claramente explicitado na paisagem. Se as usinas das Terras Altas são também modernas, a expectativa seria a de encontrar, como na Zona da Mata, além da nucleação das construções em tomo da usina, nada mais do que o vazio do habitat nos imensos canaviais.

Nas Terras Altas, no entanto, a monotonia dos canaviais é com freqüência quebrada por casas ou conjuntos de casas próximas, porém separadas umas das outras por distâncias consideráveis, de cerca de $500 \mathrm{~m}$ ou mais. Rodeadas por pequenos roçados e poucas fruteiras, correspondem ao atual sítio de 1-2 ha do trabalhador residente.

Das usinas, a Cruangi é a que maior número de casas e roçados concede aos seus moradores. A numeração própria que as fachadas das residências recebem reforça a natureza sistemática e artificial, de certa forma postiça, da distribuição dessa recriação da antiga forma do habitat, hoje tão uniforme quanto possível para fazer presente aos habitantes sua condição de empregados de uma moderna empresa.

Que mecanismos poderiam explicar sua sobrevivência, aliás bastante significativa? No caso das paleoformas funcionais, antes de mais nada, cabe buscar o sentido de sua existência e funcionalidade, tal qual se dá nas Terras Altas. Para tanto, trabalharemos o exemplo mais evidente da paleoforma funcional, dado pela citada usina. 
Inicialmente, na tentativa de compreender o paradoxo da paleoforma funcional, há que se levar em conta a nova face da plantation, cuja intensificação em capital está estruturalmente associada ao gigantismo traduzido em terras e homens e cada vez mais ligada aos tabuleiros. Em termos relativos o sistema é economizador de mão-de-obra, pelo óbvio aumento da produtividade: a lavoura canavieira ocupa espaços cuja utilização seria inexeqüível sem as máquinas. Algumas usinas têm 50 mil ha plantados. Tal expansão cria, por conta da vastidão das áreas ocupadas, a necessidade crescente de grandes contingentes de trabalhadores cujo número aumenta em termos absolutos.

Outra reflexão pertinente e mais específica é a de que as usinas das Terras Altas, mesmo modernas, se encontram em situação de desvantagem com relação à produção agrícola dada a topografia menos favorável que lhes diminui a produtividade.

Assim, a existência da paleoforma do habitat pode ser vista, por um lado, como permanência de um passado de forte tradição policultora; por outro, e principalmente, tal permanência é indicadora de mudança, fruto de uma estratégia recente das usinas e/ou fornecedores em manter um contingente considerável de mão-de-obra disponível e submissa em seu território.

No caso específico de Cruangi, as dificuldades trazidas pelo ambiente natural não se restringem apenas à topografia ondulada. Seu clima é mais seco ( $1022 \mathrm{~mm}$ anuais) sendo importante lembrar que a usina foi pioneira, na Mata Norte, na irrigação dos canaviais já nos anos 50. Além do mais, ocupando a maior parte das terras popularmente denominadas como mato seco de Timbaúba/Macaparana, conseqüentemente tem solos menos profundos.

Tais condições naturais acentuam a queda da produtividade, já bastante prejudicada pelas limitações impostas à mecanização por conta da topografia. Há, nesse quadro, uma busca de compensações, seja por emprego de mão-de-obra mais numerosa, seja por maior número de horas trabalhadas por pessoa. Sua estratégia de sobrevivência prende-se a um jogo de adaptações entre sistema agrícola e condições naturais e sociais.

A opção pela colheita de cana crua - sem a prática da queimada, 2/3 do total colhido - significa maior preservação da fauna e da vida bacteriana do solo, e a formação da cobertura morta que resulta em economia na irrigação e no consumo de adubos, inseticidas e herbicidas. Para executar o corte da cana crua, porém, é obvia a necessidade de intensificação do siste- 
ma agrícola em mão-de-obra. É preciso, pois, conseguir que o trabalhador faça mais de uma conta por dia, visto que seu trabalho rende muito menos do que com cana queimada, na proporção de 60 para 100.

É sabido que todas as usinas praticam sistemas de prêmio para estimular o trabalhador a colher uma área além da mínima estipulada em lei, isto é, a conta. Cruangi, porém, cria a vantagem, via relação de morada, de ter uma grande massa de seus empregados trabalhando maior número de horas. É mais fácil manipular trabalhadores residentes do que os da pontade-rua que, entre outros aspectos, estão mais predispostos a ouvir o Sindicato dos Trabalhadores Rurais. A lei que permite ao trabalhador em Pernambuco fazer apenas uma conta por dia é, assim, contornada. O aumento do número de pessoas contratadas significaria, igualmente, aumento no valor das indenizações por ocasião da rescisão dos contratos na entressafra. Na supressão desse gasto indesejável reside, em parte, a estratégia de manter moradores.

Além do pagamento dos prêmios por produção e de outras estratégias, a usina age no sentido de promover maior envolvimento do trabalhador residente para mantê-lo em seu território, o que se faz em grande parte com base no fantasma do desemprego da entressafra. Nessa época, diferentemente dos demais membros da família, o pai não tem o contrato rescindido.

A existência dessa situação, traduzida no habitat, tem profundas raízes históricas. A empresa tem por trás de si cinco gerações de usineiros e, provavelmente, de moradores.

A paleoforma funcional do habitat foi, na verdade, ampliada e recriada na década de 70 pelo irmão mais novo do atual diretor, quando o pai ainda era vivo e via, muito por conta de seu passado, a recriação como forma de solucionar o problema de carência de mão-de-obra. A conjuntura de então era muito favorável ao açúcar e havia necessidade crescente de trabalhadores. Tal fato mostrou-se como um dos caminhos para a manutenção de um contingente considerável de empregados, o mais longe possível de uma disputa por braços, circunstância muito nítida no início dos anos 70 e que caracterizou a "guerra de salários" (Andrade, 1981) a respeito dos corumbas, trabalhadores sazonais vindos do Agreste.

As circunstâncias, no entanto, estão mudando na atualidade e o feitiço pode se virar contra o feiticeiro. É generalizada a expulsão dos moradores em toda a zona canavieira e torna-se cada vez mais ativa a atuação do Sindicato dos Trabalhadores Rurais. Há evidente preocupação do usineiro em convencer o morador das vantagens do sistema e dos seus regulamentos. 
A questão, em grande parte, é introduzir mudanças nas relações de trabalho porque a agroindústria canavieira está num novo patamar de desenvolvimento das forças produtivas que vem tornando as Terras Altas cada vez menos viáveis devido às suas condições naturais, principalmente aquelas ligadas à topografia. Então, para viabilizar minimamente a cana-de-açúcar na área em estudo - por conta das desvantagens iniciais de obtenção da renda diferencial - é preciso alterar as relações de trabalho, o que a usina Cruangi realiza por meio da recriação do antigo sistema de morada. À medida em que essa usina puder se libertar do peso do seu passado de tradicionalismo, pensamos que a paleoforma funcional perderá sua razão de ser. Por esse motivo existe a perspectiva de sua extinção, que provavelmente ainda não ocorreu por conta da vultosa soma representada pela indenização das 750 famílias de moradores. De certa maneira a paleoforma funcional pode ser vista como uma solução provisória para o problema que a Usina Laranjeiras já resolveu totalmente com os bóia-frias e a N. S. de Lourdes com o deslocamento maciço da empresa para o tabuleiro paraibano.

A adequação entre o moderno e o tradicional, explicitada na frase do proprietário da Cruangi “antigo, mas não antiquado", significa uma adaptação com base na tradição proveniente da formação histórica das Terras Altas, bem como nas contingências do meio natural. Tal adaptação reflete-se com clareza meridiana na organização do habitat: a paleoforma funcional.

Essa forma do habitat que representa a latência, se bem que recriada de uma situação mais antiga, exprime uma relação social (morada), só que com uma população proletária residindo no local de trabalho. O usineiro mantém poder quase que absoluto sobre o trabalhador. "É uma forma específica de dominação", herança do poder senhorial. Além de materializar-se no habitat - o "continente" - esta latência é também social, bastando para tanto lembrar o direito consuetudinário evocado pelo usineiro - o "conteúdo" (George, 1982:1).

Finalmente, é importante refletir sobre as palavras de Tricart (1956) quando afirma que o habitat sobrevive às condições nas quais se organizou: evolui, então, conservando algumas de suas características originais, mas ao mesmo tempo adaptando outras às novas circunstâncias.

Se para o conjunto das usinas houve uma radical mudança do habitat, formando-se o vazio, isso significa que o antigo desapareceu quase totalmente. Só a casa-grande e o velho engenho dão conta do passado. A adaptação de Cruangi nos leva a pensar que o novo que cresceu em meio ao antigo assumiu a sua forma, ainda que transmutada. Substituiu o antigo imitando-o deliberadamente na forma e adaptando o velho conteúdo das rela- 
ções sociais às situações presentes. Diante da sutileza dessa situação particular, fica a indagação do que é original e do que é recriação.

As áreas de adensamento

do habitat dos antigos sítios de forasteiros e moradores

O terceiro padrão de paleoforma é dado por uma conformação específica de habitat que traduz a densidade demográfica superior à média regional. Corresponde, em grande parte, a conjunto de sítios de pequenos proprietários, muitos dos quais antigos foreiros e moradores do local onde adquiriram as parcelas que já ocupavam.

O retalhamento de engenhos ou partes de engenhos foi muito comum na década de 60 , não só na área em estudo como em diversos municípios da Zona da Mata. Resultou, direta ou indiretamente, das tensões que o desenvolvimento capitalista gerava no campo e cuja face mais visível, no plano político, traduzia-se na crescente insatisfação dos camponeses que passaram a lutar por seus direitos, organizando-se em Ligas e Sindicatos Rurais. Apesar do senso comum apontar como causa maior das iniciativas para o desmembramento de grandes propriedades "o temor dos senhores de engenho de perderem a terra com a agitação comunista", na realidade existiam razões menos míticas e mais favoráveis aos latifundiários do que se pode supor à primeira vista. Manuel Correia de Andrade, por exemplo, afirma que muitos senhores de engenho fizeram ótimos negócios ao vender partes de suas propriedades, consideradas pouco produtivas e desvalorizadas, por um preço acima do de mercado - quer dizer, obtiveram lucro aproveitando-se do argumento da crise social e da disposição do governo em financiar transações (3).

Page (1972), quando comenta o crescente tumulto no campo que antecedeu o golpe militar de 1964, não descarta a hipótese de que os próprios donos de terras tenham provocado invasões para que os órgãos governamentais fossem pressionados a desapropriar imóveis a preços inflacionados. Tal aspecto não significa que devamos suprimir absolutamente o medo de revoltas camponesas do rol de fatores sopesados pelos proprietários de terras nos episódios de subdivisão de seus engenhos. Devemos, no entanto, chamar a atenção para a necessidade de relativizar a importância das possíveis razões, caso a caso. A partilha por herança, por exemplo, é muitas vezes o motivo principal de desmembramento de engenhos.

Entre os exemplos de comunidades formadas a partir do desmembramento de grandes propriedades, pode-se citar Mundo Novo, Aurora, 
Independência, Chã dos Tavares, Mata Limpa e Descanso, todos na Área Nuclear. No Setor Meridional, o fenômeno ocorre em Parnaso, Primavera e Chã do Triângulo, todos em terras de antigos engenhos. Tal fato é mais raro no setor canavieiro, cujos exemplos mais expressivos pontilham a Chã de Uruçu.

Para entender a existência das comunidades de pequenos produtores, que representam um adensamento do habitat em meio ao predomínio dos canaviais e das fazendas de gado e banana, é preciso lembrar, além do processo que acabamos de descrever, que as Terras Altas sempre se caracterizaram pelo expressivo número de moradores e foreiros. Residindo no território dos grandes estabelecimentos, trabalhavam na cana, no café e em seus cultivos próprios, resultando daí, desde os primórdios, a forte densidade demográfica na zona rural da área estudada. Os atuais sitiantes constituem um resíduo da distribuição espacial clássica da população no latifúndio.

Mesmo com a saída crescente de moradores, foreiros e pequenos proprietários nos últimos 30 anos em que a terra se valorizou pelo desenvolvimento da cultura da banana (Área Nuclear e Setor Meridional), ou foi vorazmente coberta por canaviais (Setor Norte-Oriental), muitas comunidades conseguiram sobreviver. Formam, na atualidade, essa espécie de ithas de pequenos sítios, onde a principal cultura é a da banana. O habitat tende a se adensar com o crescimento das famílias e a construção de novas casas. Em alguns locais há escolas, bodegas e residências formando incipientes ruinhas que conferem ao habitat um caráter de organização linear. Tal fato nos remete a Tricart (1956), que sugere ser a dispersão organizada linear o prelúdio do grupamento.

As casas, de modo geral, são maiores que as dos moradores atuais. Construídas em alvenaria e telhas, têm chão de cimento, instalação elétrica e, por vezes, alpendres estreitos com escadaria, imitando toscamente os chalés dos engenhos. Em quase todas as residências, os banheiros se localizam na parte externa. De qualquer modo, são casas modestas e de área pequena, não havendo, no entanto, termo de comparação com o tamanho e a qualidade das casas das pontas-de-rua.

Realiza-se nessas comunidades de pequenos produtores uma agricultura diversificada, tendo como base a fruticultura, na qual a mercadoria principal é a banana. A despeito das dificuldades inerentes à pequena produção, grande parte dos agricultores consegue, assim, se manter apesar de constantemente pressionados para vender suas terras. Mesmo não sendo capaz de competir com os grandes produtores, diante da estratificação so- 
cial que permeia o processo de urbanização e que resulta num mercado menos exigente porém expressivo, esse produtor tende coerentemente a se fixar na produção de bananas de segunda. É evidente que sua situação não é boa. A pior qualidade e a pequena quantidade de suas frutas leva-o à comercialização, quase sempre desvantajosa, a preços muito baixos.

A relação de subordinação mantém-se mesmo que sejam pequenos proprietários: face à exigüidade de terra e ao crescimento da família são fornecedores de força de trabalho em primeira instância para os grandes produtores locais e, finalmente, migram para as cidades maiores. Além disso, não tendo poder de barganha, são expropriados pelo capital comercial na venda de seus produtos aos intermediários.

Em consideração final, podemos afirmar que esta paleoforma do habitat tem uma funcionalidade: a ela está subjacente o papel de viveiros de mãode-obra tanto quanto ocorreu no passado com as famílias dos moradores e dos foreiros.

\section{O habitat grupado}

\section{A ponta-de-rua: que urbano é esse?}

As cidades e vilas das Terras Altas são fortemente marcadas pela atividade agrária. Suas funções essenciais, desde os seus primórdios, estão ligadas ao setor terciário, comércio e serviços oferecidos para uma originalmente densa população rural.

Se o quadro da distribuição da população rural/urbana mudou com o esvaziamento do campo, as funções básicas desses núcleos se modificaram muito pouco. Dificilmente pode se falar em atividade industrial de alguma significação em Machados, São Vicente Férrer, Macaparana e Vicência, a não ser, no passado, quando funcionaram máquinas de beneficiamento de café e algodão. Há, sim, entre essas cidades, na ordem apresentada, uma complexidade cada vez maior no nível dos serviços, se bem que as diferenças mais sensíveis estejam entre as duas primeiras, cidades de brejo onde circula menos dinheiro e as duas últimas, mais ligadas à cana-de-açúcar. O mesmo se dá nas vilas - Siriji, Murupé, Bizarra e Pirauá - onde as funções terciárias são ainda mais elementares.

$O$ fato fundamental que marca, sem exceção, qualquer um desses núcleos, é o surgimento e aumento progressivo de bairros periféricos, as pontas-de-rua, a partir do início dos anos 60. Essas periferias constituem o local onde se aglomera não só, mas principalmente, uma população de ex- 
moradores, muitos dos quais aposentados e também, só que em número bem mais reduzido, de antigos pequenos proprietários.

Nem sempre a velocidade do crescimento foi a mesma, e os momentos de estabilização ou expansão correspondem às mudanças ocorridas na economia e na sociedade. Assim, vivemos hoje, desde o início da década de 80 , uma fase de intensa expansão das pontas-de-rua, relacionada com o que convencionamos chamar de crise dos fornecedores. Para se ter idéia da importância do fenômeno, São Vicente Férrer tem, estimadamente, em suas pontas-de-rua $1 / 3$ da população da cidade.

O rápido crescimento das periferias criou uma atividade que atualmente está muito difundida nas Terras Altas: a fabricação artesanal de tijolos (maciços) nas caieiras. A caieira, em si, é um forno rústico erguido com os próprios tijolos que serão cozidos. Às vezes encontramos pequenas caieiras junto da própria casa que está sendo construída. Caieiras maiores têm uma clientela certa: além de consumidores particulares, as prefeituras locais, interessadas em criar e reformar pontas-de-rua para melhorar a condição de habitação dos trabalhadores.

Se nos últimos tempos vem predominando a casa de tijolos em relação à casa de taipa, esta ainda persiste, estando ligada à uma população cujos recursos são mais parcos, ou não chegaram a obter algum beneficio da prefeitura local. Na parte nova da periferia de São Vicente Férrer, por exemplo - o Coque - são predominantes as construções em taipa, tal como eram no passado recente as da própria parte antiga - o Recreio - progressivamente melhoradas pela ação municipal.

Se pensarmos no que foi dito sobre as formas de dispersão do habitat, fica fácil compreender como o fenômeno da concentração demográfica nas pontas-de-rua das cidades é, sem qualquer sombra de dúvida, mais expressivo, atingindo um número muito maior de pessoas. Mesmo ao se considerar a totalidade de um bairro periférico, ele em si não é homogêneo. Há uma marcada estratificação no seu conjunto, dada, em grande parte, pela cronologia de sua formação e incorporação à cidade.

Deve-se levar em conta, porém, que a estratificação social está refletida em diversos padrões da arquitetura e da qualidade das construções na ponta-de-rua. Em São Vicente Férrer, por exemplo, em primeiro lugar nota-se o flagrante contraste entre a parte mais urbanizada do bairro do Recreio, com casas melhores, de alvenaria e chão de cimento, ruas calçadas, e a parte mais alta, de ocupação mais recente, com casas evidentemente inferiores, sem calçamento e muitas delas, nos locais mais elevados, sem 
abastecimento de água. Os próprios habitantes do Recreio discriminam a parte nova que galga a porção mais íngreme da vertente, chamando-a de Coque em alusão a uma das maiores favelas do Recife.

Não há dúvida de que às sucessivas fases de expansão dos bairros periféricos não houve possibilidade de aplicação de políticas governamentais de modo a acompanhar o seu crescimento. Não que estas inexistam, mas por conta da rapidez com que a população chega do campo.

Se a maioria das casas é modesta, de área menor e pertence a ex-moradores beneficiados pelas políticas públicas, as casas melhores pertencem a pequenos proprietários que, na maior parte, venderam suas terras e geralmente se transformaram em comerciantes dentro da periferia.

Portanto, é preciso compreender que as migrações campo/cidade vão se diferenciar no que diz respeito à própria origem social do migrante. O pequeno proprietário, que vive a realidade da fragmentação da terra por herança, defronta-se também com o fantasma da proletarização e pensa a cidade como forma de ascensão social via educação e emprego urbano. Muitos moram na cidade, mesmo sem ter vendido sua propriedade; outros, mais pobres, ao venderem suas parcas terras, vão se localizar na ponta-derua.

Por outro lado, não se pode dizer que o morador tenha exatamente perspectivas. A alternativa mais generalizada é sua exclusão das terras das grandes propriedades e a ida quase que compulsória para a ponta-de-rua. Há, porém, algumas questões que devem ser consideradas e que constituem fatores de atração. Mesmo que continue como trabalhador rural, na rua ele pode barganhar melhor seu salário, ter o conforto mínimo da água, luz, de assistência médica, educação e religião mais próximas.

É preciso ponderar que a organização dos serviços de urbanização nas pontas-de-rua é a contrapartida do esvaziamento do campo, dada pelo Estado, a fim de manter em condições mínimas a força de trabalho para as grandes propriedades. Essa solução é mais satisfatória para a classe dominante, que naturalmente elege seus representantes para os diversos cargos da esfera local.

Cabe considerar a reordenação espacial cristalizada nas pontas-de-rua como um processo que se sedimenta há pouco mais 30 anos, estando obviamente a ele subjacente a reordenação social: é importante constatar que a reprodução da força de trabalho já se realiza na ponta-de-rua há pelo menos uma geração, resultando na formação de um proletariado com peculia- 
ridades marcadas. Essa forma específica de urbanização, representando uma nova realidade agrária, é integrante do mesmo movimento no qual a força de trabalho se reproduz no meio urbano para se ocupar majoritariamente e na maior parte do tempo na zona rural.

A expressão ponta-de-rua remete a uma certa linearidade, como se fora a continuação dos extremos da rua principal. Nas Terras Altas, por conta do sítio das cidades, seja o de fundo de vale, como é o caso de São Vicente, seja o de chã , como em Macaparana, a questão se altera, basicamente, interferindo aí o valor do solo urbano. Assim, os terrenos disponíveis para a expansão da periferia são as vertentes das colinas, bastante íngremes e menos valorizadas. A ponta-de-rua sistematicamente ocupa essas áreas declivosas e o sentido do seu crescimento é dado a partir do sítio original da cidade. Enquanto em São Vicente Férrer a ponta-de-rua sobe as colinas, em Macaparana executa o movimento contrário, a partir do topo. Geralmente são terrenos desapropriados pelas prefeituras ou negociados pelo governo do estado com as usinas.

Sempre com forte interferência do poder local, a escolha do sítio é uma das formas de segregação, convivendo a rua com a ponta-de-rua que lhe é contígua. Há casos, cada vez mais freqüentes, de uma segregação mais acentuada, pela qual a ponta-de-rua está afastada da cidade. Nesse sentido, o fenômeno é menos nítido em São Vicente e alcança seu extremo em Vicência. No caso de São Vicente, por ser uma cidade de região mais pobre, o problema da desvalorização da terra pela vizinhança do bairro periférico não é tão claramente expresso.

Com o aumento das periferias a estrutura dessas cidades se torna cada vez mais heterogênea, com a acentuação dos contrastes fisionômicos e sociais. Isso, porém, não lhes retira sua unidade. Evidentemente, há fortes diferenças entre a rua, isto é, a cidade na sua parte mais antiga e sedimentada, e a ponta-de-rua, tanto pelo sítio quanto pelo padrão das habitações e particularmente pela sua função. A ponta-de-rua está organicamente ligada ao conjunto urbano: não é postiça, nem um corpo estranho, sendo freqüen-temente, além do mais, a face mais dinâmica da cidade. Tal fato é verificado com maior intensidade em São Vicente Férrer, de forma um pouco atenua-da em Macaparana e totalmente apartada em Vicência.

A segregação expressa na localização do bairro periférico não quer dizer que ele não mantenha relações com a rua, pois os serviços que a cidade oferece também são para a sua população que, apesar de pobre, constitui um mercado cada vez mais importante pelo seu crescimento. 
A paisagem urbana revela a integração progressiva da ponta-de-rua à rua mediante a construção de casas de alvenaria e da implantação de serviços urbanos, entre eles pavimentação, água, luz, telefones públicos. É necessário, então, cuidado especial no estabelecimento do que já é rua e do que ainda é ponta-de-rua. Um dos critérios é dado pelas benfeitorias e serviços descritos.

É preciso compreender o processo histórico subjacente à formação do habitat e a relação dispersão/concentração deve ser vista por esse prisma. Se nos lembrarmos da época dos bangüês, que vai criando uma densa população rural, particularmente nos fins do século XVIII e início do século XIX, verificamos ter sido essa dispersão que criou o habitat grupado; a cidade resulta e convive com um denso habitat disperso. Atualmente a concentração também convive com a dispersão, mas, enquanto o fenômeno dispersão tende ao desaparecimento, acentua-se fortemente a concentração, particularmente nas pontas-de-rua.

A organização espacial considerada - a relação rural/urbano - reflete diferentes momentos de coexistência da dispersão com a concentração. As cidades continuam a desempenhar seu papel de apoiar mecanismos de dominação próprios do capitalismo nas suas diversas etapas de desenvolvimento.

No contexto do bangüê, a cidade servia para atender a uma população rural incalculavelmente maior que a urbana e que vivia nas terras dos engenhos. Hoje a cidade muda porque os mecanismos de dominação mudaram: não interessa mais aos grandes proprietários e às usinas, na sua maioria, ter trabalhadores morando em suas terras. Novamente a solução é a cidade e, daí, o cuidado explicitado pelas políticas públicas em manter pontas-de-rua com condições mínimas de conforto e sobrevivência.

No entanto, esse novo urbano é permeado por uma carga cultural, uma latência marcadamente rural, apesar de o fenômeno ser mais manifesto entre os mais velhos. De qualquer modo, as tradições são passadas mesmo para as gerações que já nasceram em ambiente urbano.

Diante do que acabamos de expor, justifica-se a indagação que deu nome ao trabalho: "que urbano é esse?" A reflexão se prende à especificidade da ponta-de-rua, para a qual contribuem além das questões culturais as outras já relatadas. Em primeiro lugar, cabe repetir que essa população vive fundamentalmente da atividade agrária e, portanto, seus vínculos com o campo, apesar de profundamente alterados, não deixaram de existir. Muitos, mesmo no Recreio, em São Vicente Férrer, por exemplo, criam animais (até gado bovino) nos quintais de suas casas. Nesse caso, são ex-pe- 
quenos proprietários. É comum a criação de caprinos, porcos, galinhas, a cultura de hortaliças e pequenos bananais e parreirais. São heranças ainda muito significativas das origens de tal população.

Por outro lado, não se pode dizer que a forma de interação destes habitantes com a cidade se dê da mesma maneira de quando viviam no campo. A diferença básica é que anteriormente, não contando a necessidade de atendimento médico de urgência e as festas, essa população rural só vinha para a cidade uma vez por semana, no dia da feira. Agora o cotidiano é outro e a interação muito mais intensa; naturalmente o modo de pensar dessas pessoas, por conta da concentração representada pelo próprio bairro e também pela ligação com a rua, vai mudar muito mais rapidamente no sentido da formação de hábitos e padrões de comportamento urbano.

Além dos serviços elementares, há a praça, o ponto de encontro nos fins de semana; há o cinema, mesmo que seja um modesto ambiente com videocassete; há o contato permanente com uma série de serviços (bares, lanchonetes, supermercados) e instituições como o Sindicato dos Trabalhadores Rurais, antes inimaginável. Esse homem urbano, trabalhador rural, é um dos exemplos mais didáticos da eficácia do modelo econômico. Interessa às usinas suas terras vazias, como interessava antes ao senhor de engenho suas terras com foreiros e moradores. A solução também é boa no sentido de que a concentração favorece a escolha; fica fácil obter e selecionar trabalhadores nesses aglomerados cada vez maiores e com muita mãode-obra excedente.

Não só a cidade é funcional, mas toda a organização do espaço. Aliás, devemos ter bem claro que a mola impulsionadora dessas mudanças nas cidades partiu das transformações do agrário. As cidades das Terras Altas são mais um dos instrumentos participantes desta nova face da plantation.

\section{Da rua sem ponta-de-rua}

\section{à ponta-de-rua sem rua}

Com tal subtítulo, pretende-se demonstrar como formas tão diferentes e até mesmo contraditórias do habitat podem, conforme o caráter variável de cada local, ser interpretadas no sentido de que fazem parte de um mesmo processo histórico geral. Para tanto tomamos dois exemplos opostos, Vicência e Chã do Esquecido.

No caso de Vicência, o fenômeno da segregação alcança seu mais alto grau. As antigas pontas-de-rua foram gradualmente incorporadas à rua, e mesmo sendo modestas as casas, pertencem às famílias de classe média 
baixa e não à população proletária. É sabido que Vicência é uma cidade muito ligada à cana-de-açúcar, sofrendo influência direta da Usina Laranjeiras.

A solução encontrada pelas elites e por seus representantes na cidade foi no sentido de preservar ao máximo o valor dos imóveis urbanos, afastando uma vizinhança indesejável. Os terrenos obtidos pela municipalidade destinam-se a loteamentos para conjuntos habitacionais de classe média baixa ou a outros de classe média ou de classe média alta. Assim, a prefeitura estimulou um processo, já de certa forma espontâneo, de fixação do proletariado rural em pontas-de-rua representadas pela vila de Murupé e pelo povoado de Borracha, respectivamente a 15 e $20 \mathrm{~km}$ de Vicência. O primeiro tem estimadamente três mil habitantes e o segundo cerca de dois mil.

Borracha e Murupé tiveram nos últimos tempos um crescimento muito forte, evidentemente das pontas-de-rua. Mas esse crescimento não foi acompanhado de melhoria da atividade comercial; pelo contrário, esta se encontra nitidamente decadente, com armazéns fechados, feiras reduzidas e pouco movimento.

Na época dos bangüês, aglomerados como os de Murupé e Borracha, tanto quanto o de Bizarra, mostravam um comércio ativo, cujo movimento era baseado principalmente na existência de foreiros e moradores dos engenhos próximos. Eram eles, ao mesmo tempo, produtores de gêneros alimentícios e compradores de produtos industrializados.

O desmantelamento dessa forma de organização econômica significou a progressiva perda de vitalidade de tais povoações até que a atividade comercial, função razão de ser das mesmas, se reduzisse ao mínimo. Tudo passa a ser comprado nas cidades e a rua e seu comércio vivem quase que do passado. Para tanto também contribuiu a melhoria das estradas que passaram a facilitar o acesso às cidades maiores. Todavia as vilas têm, tanto quanto as cidades, uma face altamente dinâmica dada pela população proletária ligada ao crescimento cada vez maior das periferias.

O exemplo mais didático de Vicência, no sentido de que aí a segregação é maior, nos traz à mente uma questão fundamental, que não se prende apenas a essa, mas às demais cidades: trata-se das modificações dos mecanismos de manutenção do poder no rastro das profundas transformações sócio-espaciais que têm uma das suas melhores expressões no habitat.

Que relação poderia existir entre mudanças do habitat e as novas formas de controle político? Considerando-se a época dos bangüês é fácil compreender como o senhor de engenho, todo-poderoso, manipulava, 
mediante a concessão da morada, a massa de seus moradores e foreiros, caracterizando muito bem o curral eleitoral que conduzia à prefeitura o representante do chefe politico local.

Sem dúvida, a passagem de um habitat disperso para uma forma predominantemente concentrada traz adaptações por parte das elites à nova situação e uma das estratégias mais comuns é a promessa de cessão de lotes nas pontas-de-rua, como ficou evidente no caso de Borracha e Murupé. A dominação se perpetua calcada na concessão da terra para a morada, não obstante as profundas transformações das relações sociais e do habitat. A essa forma de segregação tão marcada em Vicência convencionamos chamar de rua sem ponta-de-rua.

Na relação entre o habitat disperso e o grupado devemos considerar um outro caso muito particular que ocorre em Chã do Esquecido, município de São Vicente Férrer. Trata se de um fenômeno único nas Terras Altas: o da existência de uma ponta-de-rua sem que exista a cidade. É uma área densamente povoada por pequenos proprietários, produtores de banana e uva e que, em grande parte, são capitalizados.

Em Chã do Esquecido há uma forma incipiente de concentração, constituída pela sede da velha fazenda, pelo armazém, pela igreja, por um mercadinho, por maternidade, escola primária e algumas residências rurais próximas. Não se pode chamá-la sequer de povoado.

A ponta-de-rua, conhecida como Alto de Santa Terezinha, localizase no topo de uma das colinas da área; é de dimensões reduzidas, contando com 45 casas das quais $80 \%$ são de taipa, a maioria de chão de terra batida e as cozinhas externas - puxadas toscas nos fundos da casa. É um arruado sem qualquer calçamento, em parte sem energia elétrica e sem abastecimento d'água. O Alto de Santa Terezinha é, indubitavelmente, a ponta-derua mais miserável que pudemos observar ao longo da pesquisa.

Como explicar então a existência do fenômeno? Não se pode pensar numa forma de segregação do urbano porque ele aí simplesmente não existe. A explicação é outra. Essa ponta-de-rua formou-se no final da década de 80, não só com ex-moradores de Chã do Esquecido, mas de lugares próximos, no Agreste seco, onde alguns proprietários locais também possuem terra.

O terreno foi cedido por seis proprietários de Chã do Esquecido, os mais abastados, e as pessoas que aí residem, geralmente trabalham para cada um deles. É como se fossem moradores fora das terras do patrão. Muitos dos proprietários, especialmente os que cederam as terras para a 
construção da ponta-de-rua, têm ou tiveram moradores nas suas pequenas propriedades.

A concentração foi criada por uma forma dispersa do habitat, de pequenas unidades capitalizadas, pequenas empresas agrícolas. Mesmo que para a maior parte dos produtores o trabalho familiar ainda seja importante, eles mantém mão-de-obra permanente trabalhando em seus parreirais e bananais. Alguns, com suas propriedades de 10, 15 ha (consideradas acima da média) continuam com um ou mais moradores na propriedade. Outros, sequer são agricultores e todo o serviço é feito por trabalhadores assalariados temporários e permanentes. Muitos deles têm seus empregados morando no Alto de Santa Terezinha.

Quais as raízes históricas que podem ajudar na compreensão do fenômeno? O sistema agrícola nas pequenas propriedades em Chã do Esquecido é fortemente intensivo de mão-de-obra, apesar da capitalização nos meios de produção. Por esse motivo o assalariamento permanente é necessário, inclusive com moradores nas pequenas propriedades. Caracteriza-se, assim, a existência de relações capitalistas no interior da unidade familiar de produção.

Deve ser levado em conta, também, o passado da região em estudo, no qual as antigas fazendas de café, com seus moradores, foram se fragmentando, gerando grande número de pequenas propriedades e, ao mesmo tempo, fortes contingentes de trabalhadores sem terra, homens livres, que se empregam nas fazendas, nos engenhos e também nas pequenas propriedades, na esteira da tradição. Essa é uma história marcada pela plantation, que no presente caso desintegrou-se, mas manteve, mesmo com a atomização em pequenas propriedades, a relação de morada, que traduz uma relação de dominação.

A comunidade de pequenos proprietários de Chã do Esquecido repete, em ponto menor, o que fazem as usinas, isto é, ao mesmo tempo em que precisam de trabalhadores, eles também preferem mantê-los fora de suas terras. Só que neste caso, o urbano não existe. A ponta-de-rua sem rua é uma forma de evitar que as pessoas vão para o Coque ou o Recreio, em São Vicente Férrer.

\section{Conclusão}

Ao longo do trabalho objetivou-se mostrar que, para cada época, as formas de dominação estabelecidas sempre se manifestaram, entre outros aspectos, no habitat como a morada do homem e, neste sentido, expressão 
das relações sociais de produção prevalecentes em dado contexto histórico. Desde o tempo do bangüê, com os foreiros e moradores, a relação de subordinação expressava-se pela concessão de morada e de terra para cultivo. Desse modo, uma população sem terra via satisfeita a sua necessidade de segurança, ao mesmo tempo em que eram atendidos os requerimentos de mão-de-obra do engenho.

O engenho, necessariamente, criava um habitat rural disperso e cada vez mais denso. No caso particular das Terras Altas, onde ressalta a presença do Brejo de São Vicente, o povoamento não foge à regra geral: os brejos são áreas de densidade demográfica muito forte, o que acontece até hoje, apesar de redução bastante acentuada. Assim, uma das heranças mais comuns deste passado é o número muito grande de pequenas cidades, vilas e povoados, separados por distancias reduzidas.

A lógica do sistema, traduzida na dominação de classes, permanece e se mostra na face mais dinâmica das cidades: as pontas-de-rua que abrigam os trabalhadores dos canaviais e bananais e, de certa forma, contribuem para sustentar a função comercial urbana. Então, tal urbano tem de ser visto hoje muito mais como um repositório e um viveiro de mão-de-obra, com todas as particularidades que apontamos, desde as suas origens, suas formas de crescimento e integração com a rua. Tudo isso nos leva à reflexão traduzida na pergunta "que urbano é esse?" Na verdade, a indagação pode ser feita de outra forma, mas com o mesmo sentido: "que rural é esse?"

Nessa linha de pensamento cabe considerar que o habitat tem importância paramétrica por consistir num dos elementos mais evidentes e mais fáceis de se perceber o conteúdo das relações de dominação, seja por meio do antigo - a concessão da morada e do roçado diretamente pelo senhor de engenho - seja pelo novo, por promessas de concessão de lotes nas pontasde-rua em períodos eleitorais, por candidatos dos grandes proprietários.

A análise das diferentes etapas da evolução do capitalismo - desde os engenhos bangüês até os surtos usineiros - mostrou necessidades diversas e, portanto, diferentes estratégias da grande produção que se moderniza para resolver os problemas relativos à mão-de-obra, implicando também solucionar a questão das condições de moradia dos trabalhadores.

O desmantelamento da pequena produção que formava o habitat disperso dos engenhos não significou absolutamente que os grandes proprietários deixassem de manter relação de dominação, só que agora com uma população proletária rural vivendo em habitat urbano. 
Mesmo em escala tão pequena quanto a representada pelas Terras Altas, apesar de ser possível fazermos generalizações sobre o habitat ao longo da história, notam-se particularidades na sua estruturação. Tais particularidades, às vezes exemplos que constituem situações diametralmente opostas, como os casos de Vicência e Chã do Esquecido ou a paleoforma e a ponta-de-rua, não ocorrem por acaso. Tais situações estão ligadas inicialmente a um caráter muito particular desse espaço, que é a sua grande diversidade do ponto de vista do ambiente natural.

Essa diversidade, aliada às características próprias do povoamento da Mata Norte - posterior e com senhores de engenho menos capitalizados que na Mata Sul -, dá-lhe cor própria, fisionomia específica. Assim, não é difícil compreender como numa área periférica, no caso Chã do Esquecido, pode-se realizar o paradoxo da ponta-de-rua sem rua e como a lógica do sistema capitalista funciona de maneira adequada a diferentes realidades naturais e sociais. O mesmo sistema cria, só que em escala de produção de riqueza absolutamente incomparável com a dos pequenos produtores de Chã do Esquecido, um exemplo máximo de segregação em Vicência, o que convencionamos chamar de rua sem ponta-de-rua.

Outra questão diretamente relacionada com o habitat, que é a existência das paleoformas, não foge do que acabamos de dizer. A sobrevivência ou recriação das formas antigas do habitat tem a ver não só com o processo histórico de desenvolvimento capitalista nas Terras Altas, mas também com suas particularidades ambientais. Tais particularidades, de uma forma ou de outra, acabam por interferir no desenvolvimento das forças produtivas, com reflexos no estabelecimento de relações sociais de produção que fogem completamente do padrão atual de ocupação das Terras Altas.

As paleoformas traduzem no espaço o que poderia parecer a negação da ponta-de-rua, mas no fundo representam formas de adaptação de um mesmo processo, se bem que as primeiras são um resíduo e a segunda está em franca expansão. Ambas refletem, porém, uma situação social dramática, resultante da chamada modernização da agricultura.

Notas

1 A ponta-de-rua é um bairro residencial ocupado maciçamente por população proletária, com a particularidade de que na sua maioria esmagadora é constituída por trabalhadores rurais assalariados e sazonais 
2 Não ocorre por acaso o sentimento de hostilidade e a atitude de enfrentamento nutridos pelos usineiros e fornecedores em relação aos sindicatos rurais.

3 Entrevista concedida à equipe de pesquisa na sede da Fundaj, Recife/PE, em $08 / 03 / 93$.

Referências bibliográficas

ANDRADE, B. X. (coord.). Migrações sazonais no Nordeste (relatório de pesquisa). Recife, Sudene/UFPE, 1981.

ANDRADE, M.C.A. A terra e o homem no Nordeste. São Paulo, Brasiliense, 1963. - O vale do Siriji. Recife: Museu do Açúcar, 1971. Revista do Museu do Açúcar. Recife, ano IV, v. 1, n. 6, 1971 [separata].

História das usinas de açúcar de Pernambuco. Recife, Massangana/Fundaj, 1989.

CARVALHO, I.M.M. \& LANIADO, R.M. Transição democrática, políticas públicas e movimentos sociais. In: MOURA, A.S. (org.). O Estado e as politicas públicas na transição democrática. Recife, Massangana/Fundaj, 1989.

DENIS, P. O Brazil no Século XX (versão portuguesa). Lisboa, José Bastos \& Cia. $\mathrm{s} / \mathrm{d}$.

GEORGE, P. La campagne: le fait rural a travers le monde. Paris, P.U.F, 1956.

Os métodos da geografia. São Paulo, Difusão Européia do Livro. Coleção Saber atual n. 151, 1972.

População e Povoamento. São Paulo, Difel, 1972.

As bases geográficas da sociologia rural. In: SZMRECSANYI, T. \& QUEDA, O. (orgs.). Vida rural e mudança social: leituras básicas de sociologia rural, 3ª ed. São Paulo, Nacional, 1979.

. Geografia rural. São Paulo, Difel, 1982.

GRABOIS, J. \& Silva, M.J. O brejo de Natuba: estudo da organização de um espaço periférico. Rio de Janeiro, IBGE, Revista Brasileira de Geografia, v. 53, n. 2, 1991 .

GRABOIS, J.; SILVA, M.J \& MACIEL, C.A.A. Reordenação espacial e evolução da economia agrária: o caso das Terras Altas de Transição Agreste/Mata do Norte de Pernambuco. Rio de Janeiro, IBGE, Revista Brasileira de Geografia, v. 54, n. $1,1992$.

HARTSHORNE, R. Propósitos e natureza da geografia. São Paulo, Hucitec, 1978. 
HEREDIA, B.M. Alásia. A morada da vida: trabalho familiar de pequenos produtores no Nordeste do Brasil. Rio de Janeiro, Paz e Terra, 1989.

Formas de dominação e espaço social: a modernização da agroindústria canavieira em Alagoas. São Paulo, Marco Zero/MTC/CNPq, 1989.

LACOSTE, Y. L'enquête et le terrain: un probléme politique por les chercheurs, les étudiants et les citoyens. Paris, Herodote, n. 8, p. 3-20, out./dez. 1977.

MARTINS, J.S. O cativeiro da terra. São Paulo, Livraria Editora Ciências Humanas, 1979.

MELLO, M.C.O Bóia-fria: acumulação e miséria. Petrópolis, Vozes, 1975.

MONBEIG, P. Pionners et planteurs de São Paulo. Paris, Armand Colin, 1952.

PAGE, J.A. A revolução que nunca houve. O Nordeste do Brasil, 1955-1964. Rio de Janeiro, Record, 1972.

PRADO JR., C. A questão agrária no Brasil. São Paulo, Brasiliense, 1979.

SALES, T. Agreste, agrestes: transformações recentes na agricultura nordestina. Rio de Janeiro, Paz e Terra/Cebrap, 1982.

SANTOS, J.V.T. Colonos do vinho: estudo sobre a subordinação do trabalho camponês ao capital. São Paulo, Hucitec, 1978.

SIGAUD, L. Os clandestinos e os direitos: estudo sobre os trabalhadores da cana-deaçúcar de Pernambuco. São Paulo, Duas Cidades, 1979.

SILVA, J. G. et al. Estrutura agrária e produção de subsistência na agricultura brasileira, $2^{a}$ ed. São Paulo, Hucitec, 1980.

SILVA, J.G. A modernização dolorosa: estrutura agrária, fronteira agricola e trabalhadores rurais no Brasil. Rio de Janeiro, Zahar, 1982.

SORRE, M. Les fondements de la géographie humaine. Paris, Armand Colin. t. III: L’habitat - Conclusion génerale, 1952.

TRICART, J. Cours de géographie humaine. L'habitat rural. $2^{\text {éme }}$ ed. Paris, C.D.U., fascicule I, 1956.

VALVERDE, O. O noroeste da Mata Pernambucana (a região de Timbaúba). Rio de Janeiro, 1961. Boletim Carioca de Geografia, ano XIII, n¹/2.

WAIBEL, L. Princípios da colonização européia no Sul do Brasil. In: Capitulos de geografia tropical e do Brasil. Rio de Janeiro, IBGE, 1958.

WANDERLEY, M.N.B. Capital e propriedade fundiária: suas articulações na economia de Pernambuco. Rio de Janeiro, Paz e Terra, 1979. 
RESUMO - ESTE TRABALHO CONSISTE numa tentativa de resgatar, para a Geografia, o assunto habitat rural, não de maneira descritiva, mas dentro de uma perspectiva histórica que ligue as formas do habitat e suas transformações ao desenvolvimento das forças produtivas e à evolução das relações sociais de produção. A proposta da pesquisa é demonstrar como o surgimento e a evolução do habitat existente nas Terras Altas da Transição Agreste/Mata do Norte de Pernambuco, especialmente aquele ligado à pequena produção, encontram-se fortemente vinculados à histórica relação de subordinação dos pequenos produtores à grande produção. Para tanto, tratou-se de caracterizar a produção camponesa, parte substancial da referida pequena produção. O engenho bangüê, exprimindo relações capitalistas de produção, cria no seu interior uma forma de produção camponesa representada mais caracteristicamente pelos foreiros. Os moradores não chegavam a representar unidades de produção camponesa. Estavam muito mais ligados ao trabalho coletivo, isto é, ao canavial. Assalariados, formavam a parte fundamental da força de trabalho empregada no engenho. Assim, os bangüês engendraram numerosas unidades de pequena produção traduzidas num habitat disperso, cujo adensamento acabou por criar pequenos centros urbanos locais. Com o surto usineiro, o capitalismo, na sua evolução, redefiniu as antigas relações de trabalho e morada, desmantelando esse universo de pequenos produtores e transformando sua grande maioria em proletários. Tais fatos sempre se refletiram fielmente na organização do habitat rural e urbano; a resposta que se observa na organização espacial é também uma redefinição do habitat, com o surgimento e crescimento das pontas-de-rua a permanência de formas residuais, as paleoformas. Esse urbano tem de ser visto hoje como um repositório, um viveiro de mão-de-obra. Aí vive uma população proletária que trabalha fundamentalmente no meio rural. Somando-se a isso a velocidade com que a população se deslocou do campo para a cidade nos últimos 30 anos, chegamos à reflexão que deu título ao trabalho: "que urbano é esse?".

RÉSUMÉ - LE BUT DE CE TRAVAIL est de tenter de réintroduire le thème de l'habitat rural en Géographie, évitant un traitement descriptif et privilégiant une démarche historique qui relie les formes d'habitat et leus transformations au développement des forces productives et à l'évolution des relations sociales de production. La recherche vise à démontrer que l'émergence et l'évolution de l'habitat des Hautes Terres de la transition Agreste/Mata Norte du Pernambouc, en particulier de celui lié à la petite production, sont fortement déterminées par la relation historique de subordination des petits producteurs à la grande production. Dans ce but on a caracterisé la production paysanne, partie substantielle de la dite petite production. Le moulin à sucre bangüêe expression de relations capitalistes de production, crée en son sein une forme de production paysanne représentée particulierèment par les foreiros (tenanciers). Les moradores(occupants à titre gratuit) le constituaient pas des unités de production paysanne. Ils étaient beaucoup plus liés au travail collectif, c'est à dire aux cannaies. En tant que salariés ils formaient une partie fondamental de la force de travail employée a la plantation. Ainsi ces plantations 
bangüês ont fait naître de nombrenses unités de petite production représentée par un habitat dispersé qui lorsqu'il devient plus dense finit par créer de petits centres urbains locaux. Avec l'industrialisation de la production du sucre en usines, le capitalisme a redéfini, dans son évolution, les anciennes relations de travail et d'habitation; il a demantelé cet univers de petits producteurs et les a transformés dans leur plus grand nombre en proletaires. Ces faits se sont toujours reflétés fidélement dans l'organisation de l'habitat rural et urbain; la réponse observée dans l'organisation spatiale correspond aussi à une redefinition de l'habitat, avec la naissance et augmentation des périphéries (pontas-de-rua) et la permanence des formes residuaires, les paleoformes. Ce milieu urbain doit être perçu aujourd'hui en tant que dépôt et pépinière de main d'oeuvre. Lá vit une population prolétaire qui travaille pour l'essentiel dans le milieu rural. Aditionnant cela à la rapidité avec laquelle la population s'est transférée de la campagne vers la ville durant les derniers trente ans, nons pouvons comprenere la réflexion qui a donné son titre à ce travail: "de quel urbain s'agit il?"

José Grabois é professor titular de Geografia Humana, aposentado da Universidade Federal Fluminense e professor adjunto do Instituto de Geociências da Universidade do Estado do Rio de Janeiro. Pesquisador CNPq. 